Original Research

\title{
Analysis of Influencing Factors of Ground-Source Heat Pump Applications in China Using Partial Least Squares Regression
}

\author{
Yong Jiang ${ }^{1-2}$, Yalin Lei ${ }^{1-2 *}$ \\ ${ }^{1}$ School of Humanities and Economic Management, China University of Geosciences, \\ Beijing, 10083, China \\ ${ }^{2}$ Key Laboratory of Carrying Capacity Assessment for Resources and the Environment, \\ Ministry of Land and Resources, Beijing, 100083, China
}

Received: 3 March 2017

Accepted: 11 April 2017

\begin{abstract}
Energy crisis and environmental pollution have become major challenges in China's economic development, which has triggered the demand for alternative energy sources and promoted the popularization of ground source heat pump technology. A ground source heat pump (GSHP) is a central heating and/or cooling system that transfers heat to or from the ground. It uses the earth as a heat source (in the winter) or a heat sink (in the summer). This design takes advantage of the moderate temperatures in the ground to boost efficiency and reduce the operational costs of heating and cooling systems. This paper adopted the STIRPAT model and the influencing factors were analyzed. The major influencing factors were population (P), urbanization level (U), GDP per capita (A), energy consumption per capita (E), industrial structure (IS), R\&D (T), central heating area (HA), and policy investment (PI). However, these factors themselves had strong collinearity, which might produce some uncertain impacts on the final results. To avoid the impact of collinearity, the method of partial least squares (PLS) was used. The results showed that P, U, A, E, T, HA, and PI had positive effects on GSHP, while IS had a slight effect on GSHP. This paper found that A is the most dominant factor and the effect of the IS could almost be ignored. Some policy recommendations were given on how to promote the application of GSHP systems and mitigate the growth of $\mathrm{CO}_{2}$ emissions.
\end{abstract}

Keywords: ground source heat pump (GSHP), partial least squares(PLS), influencing factors, Chinaspline

\section{Introduction}

The increase in energy consumption in the building sector potentially threatens the end users of energy [1].

*e-mail: leiyalin@cugb.edu.cn
The building sector accounted for about $27.8 \%$ of the total energy consumption in China in 2010, 65\% of which was attributed to heating, ventilation, and air conditioning [2-4]. Of the natural resources available to replace electricity to reduce carbon emissions associated with heating, ventilation, and air conditioning, ground source heat represents one of the most remarkable options [5]. A ground source heat pump (GSHP) offers an attractive 
option for heating and cooling residential and commercial buildings because of its higher energy efficiency over conventional systems [6-7]. An analysis was performed to estimate the total equivalent warning impact (TEWI) of a GSHP compared to other heating and cooling systems in residential, commercial, and institutional buildings. The modeling results show a $\mathrm{CO}_{2}$ emission reduction from $15 \%$ to $77 \%$ through the application of a GSHP in both residential and commercial buildings [8]. With increasing proportions of electricity generated from renewable sources, installing heat pumps in existing buildings becomes a more and more attractive option with respect to both primary energy demand and $\mathrm{CO}_{2}$ emissions.

To promote the use of renewable energy, the Chinese government formulated a series of policies and regulations. In 2002 the Ministry of Land and Resources pointed out that geothermal resources were one of the most important forms of clean energy. Implementing the Renewable Energy Law in 2006, the government explicitly stated the importance of GSHP development and listed the installation of GSHPs as key projects in the Guidelines of Renewable Energy for industry development. By the end of 2012, more than 100 policies geared toward promoting GSHPs have been issued by the Chinese government [9]. In addition to these policies, the Chinese government also legislated various standards to guide the design, installation, and testing of GSHP systems. Issued in 2005 and revised in 2009, technical specifications for the ground source pump system (GB 50366-2005) are characterized by unified terminologies and an installation approach for GSHP systems. GB-T19409-2013 focuses on the testing, inspection, transportation, and storage of GSHP systems.

Scholars have done extensive research on the technologies that affect GSHPs in China. They adopted the quantitative and qualitative methods to analyze the coefficient of performance (COP) of GSHPs and make an economic assessment of GSHP systems. While the technical feasibility of a GSHP system may be visible in most studies of renewable energy, the risk and initial investment of GSHPs are very high and the benefits achieved by a GSHP system cannot be realized for 10 to 30 years. Furthermore, there has been no macroeconomic analysis on the development and use of the GSHP system. To promote the GSHP application, the basic challenge is to determine the factors that affect the GSHP. Therefore, this paper intends to use STIRPAT and the partial least squares (PLS) method to evaluate the GSHP application. Section 2 is a review of the literature concerning GSHPs and some countries' experiences with GSHP systems are presented. In section 3, the methodologies of STIRPAT and PLS are introduced. Section 4 focuses on the characteristics of the effect on GSHP applications, describes the PLS model to set the model for GSHPs, and analyzes the various influencing factors affecting the GSHP system. Section 5 draws some interesting conclusions and presents recommendations.

\section{Literature Review}

Some studies have been conducted to assess the energy performance of GSHP systems. Luo et al. (2015) examined the thermal performance of a GSHP system and found that COP was estimated to be 3.9 for a typical winter day, while the energy efficiency ratio (EER) was assessed to be 8.0 for a typical summer day [10]. Zhang et al. (2015) investigated the influence of how space heating and cooling demand was quantified on the potential utility of GSHP systems and found that the operational variation of COP influenced the electricity consumption of the GSHP systems [11]. Kecebas A (2013) dealt with energetic and exergetic analyses as well as economic and environmental evaluations of an Afyon geothermal district heating system (AGDHS) in Afyon, Turkey [12]. Blum et al. (2011) and Col et al. (2015) assessed the technical and economic factors that influence the design and performance of GSHP systems [13-14]. Wang et al. (2016), Mehrizi et al. (2016), and Soni et al. (2016) studied the influence of the ground source heat exchanger on a GSHP system [15-17]. Noorollahi et al. (2016) indicated that the longer the ground heat exchanger was, the higher the capacity of GSHPs [18]. Qian et al. (2014) calculated the soil temperature distribution and the COP of GSHPs and investigated different scenarios that were simulated to quantify the impact of different factors on GSHP performance, including seasonal balance between heat collection and heat rejection, daily running mode, and spacing between boreholes. Energy performance of GSHP systems are affected by various factors and the COP of GSHP systems fluctuated during the operation [19].

With respect to the economic evaluation of GSHPs, there are a number of economic analysis methods used to evaluate their economic performance. These include the life cycle cost method, the net benefits (net present worth) method, the payback method, the benefit-to-cost (or savings-to-investment) ratio method, the internal rateof-return method, the overall rate-of-return method, the energy and cost energy mass method, and the analytical hierarchy process [20].

For their example in Sapporo, Japan, Nagano et al. (2006) found that the payback time for the increased investment cost of a GSHP system is 10 years in comparison with an oil boiler and an air conditioning (AC) system, nine years in comparison with a gas boiler and an AC system, and 14 years in comparison with an air conditioning heat pump system [21]. Esen et al. (2006) presented a detailed cost analysis with payback periods. They indicated that the payback period of the GSHP would be 8.38 years against the electric systems [22]. Morrone et al. (2014) calculated the amount of energy saved by comparing the actual GSHP systems with traditional heating and cooling systems together [23]. Kecebas et al. (2013) proposed an artificial neural network technique as a new approach to evaluate the energy input, losses, output, efficiency, and economic optimization of 
a geothermal district heating system [24]. Badescu V(2007) compared the economics of GSHPs with a conventional HVAC system for a residential house in Germany using the present-day costs method [25].

Some scholars have carried out assessments of the social effects of a GSHP application:

Shen et al. (2015) studied the performance of GSHP in future climate conditions (2040-69) by using projected future hourly weather data of selected representative cities in the United States to estimate future ground temperature change [26].

Greening B (2012) presented a life cycle assessment of domestic heat pumps in the United Kingdom in comparison with gas boilers and found that heat pumps had higher environmental impacts than gas boilers due to the use of electricity [27].

Koroneos et al. (2017) quantified the environmental impacts of the installation of a ground heat exchangerbased system in the town hall of Pylaia in Thessaloniki, Greece, by using a life cycle assessment [28].

Russo et al. (2009) calculated significant potential savings in energy use and $\mathrm{CO}_{2}$ emissions from the use of lowenthalpy geothermal technologies for space heating and air conditioning in Italy [29].

Blum et al. (2010) assessed the total $\mathrm{CO}_{2}$ savings of GSHP systems in a state in southern Germany [30].

Saini et al. (2009) assessed the social, economic and environmental impacts related to renewable energy systems in India [31].

Bayer et al. (2012) calculated the emissions savings from using GSHPs and found it reached more than $1 \%$ compared to standard heating systems in Switzerland [32].
Carcalho et al. (2015) found that the large-scale use of heat pumps for space heating in buildings could contribute to significant primary energy and $\mathrm{CO}_{2}$ emissions savings when compared to natural gas boilers [33].

Sivasakthivel et al. (2015) estimated the possible energy savings and reduction in $\mathrm{CO}_{2}$ emissions by using GSHP technology for space heating and cooling applications in cities located in and around the Himalayan region [34].

Kharseh et al. (2015) indicated that global climate change affected the performance of GSHP systems and the magnitude of this impact on a given GSHP system strongly depended on local weather conditions and the thermal quality of the building envelope [35].

On the basis of the literature review and to the authors' best knowledge, there are no studies on macroeconomic analysis and influencing factors of GSHP application. The main objective of this study is, therefore, to evaluate the influencing factors of a GSHP system at the macroeconomic level and adopt the STIRPAT and PLS methods to assess how population, urbanization, GDP per capita, industrial structure, and policies effect GSHP systems.

\section{Material and Methods}

\section{Data}

The data from the area of the GSHP application and the central heating area from 1998 to 2011 is derived from the Statistical Yearbook of the Ministry of Construction. The data on per capita energy consumption, GDP per capita, urbanization level, industrial structure, and the R\&D data

Table 1. Floor area of GSHP projects and influencing factor.

\begin{tabular}{|c|c|c|c|c|c|c|c|c|c|}
\hline \multirow{2}{*}{ Year } & $\begin{array}{c}\text { Floor area } \\
\text { of GSHP } \\
\text { Projects }\end{array}$ & Population & $\begin{array}{c}\text { Urbani- } \\
\text { zation }\end{array}$ & $\begin{array}{c}\text { GDP per } \\
\text { capita }\end{array}$ & $\begin{array}{c}\text { Energy } \\
\text { consumption } \\
\text { per capita }\end{array}$ & $\begin{array}{c}\text { Industrial } \\
\text { structure }\end{array}$ & R\&D & $\begin{array}{c}\text { Central } \\
\text { heating area }\end{array}$ & $\begin{array}{c}\text { GSHP/ } \\
\text { Central } \\
\text { heating area }\end{array}$ \\
\hline & $10^{4} \mathrm{~m}^{2}$ & $10^{4}$ & $\%$ & RMB & Kg ce & $\%$ & RMB $10^{8}$ & $10^{4} \mathrm{~m}^{2}$ & $\%$ \\
\hline 1998 & GSHP & $\mathrm{P}$ & $\mathrm{U}$ & $\mathrm{A}$ & $\mathrm{E}$ & $\mathrm{IS}$ & $\mathrm{T}$ & HA & \\
\hline 1999 & 500 & $37,411.8$ & 33.35 & $6,803.70$ & $1,021.0$ & 45.8 & 551.12 & $86,540.00$ & $0.23 \%$ \\
\hline 2000 & 500 & $37,590.0$ & 34.78 & $7,169.93$ & $1,077.0$ & 45.4 & 678.91 & $96,774.83$ & $0.52 \%$ \\
\hline 2001 & 600 & $35,747.3$ & 37.66 & $8,640.05$ & $1,182.6$ & 44.8 & 1042.49 & $146,328.91$ & $0.41 \%$ \\
\hline 2002 & 900 & $35,219.6$ & 39.09 & $9,419.94$ & $1,245.2$ & 44.5 & 1287.64 & $155,567.00$ & $0.58 \%$ \\
\hline 2003 & 1000 & $33,805.0$ & 40.53 & $10,567.81$ & $1,426.5$ & 45.6 & $1,539.63$ & $188,956.00$ & $0.53 \%$ \\
\hline 2004 & 1100 & $34,147.4$ & 41.76 & $12,363.79$ & $1,646.9$ & 45.9 & $1,966.33$ & $216,266.00$ & $0.51 \%$ \\
\hline 2005 & 1900 & $35,923.7$ & 42.99 & $14,217.00$ & $1,810.2$ & 47.0 & $2,449.97$ & $252,056.00$ & $0.75 \%$ \\
\hline 2006 & 2600 & $33,288.7$ & 44.34 & $16,558.38$ & $1,973.1$ & 47.6 & $3,003.10$ & $265,853.00$ & $0.98 \%$ \\
\hline 2007 & 8000 & $33,577.0$ & 45.89 & $20,284.68$ & $2,128.5$ & 46.9 & $3,710.24$ & $300,591.00$ & $2.66 \%$ \\
\hline 2008 & 11000 & $33,471.1$ & 46.99 & $23,851.43$ & $2,200.2$ & 46.9 & $4,616.02$ & $348,948.00$ & $3.15 \%$ \\
\hline 2009 & 16000 & $34,068.9$ & 48.34 & $25,899.53$ & $2,303.2$ & 45.9 & $5,802.11$ & $379,574.00$ & $4.22 \%$ \\
\hline 2010 & 22700 & $35,373.5$ & 49.95 & $30,494.44$ & $2,429.1$ & 46.4 & $7,062.58$ & $435,668.00$ & $5.21 \%$ \\
\hline 2011 & 24000 & $35,425.6$ & 51.27 & $35,931.53$ & $2,589.0$ & 46.4 & $8,687.00$ & $473,784.00$ & $5.07 \%$ \\
\hline
\end{tabular}


come from the China Statistical Yearbook of 1998-2011 (Table 1).

\section{STIRPAT Model}

The effect of demographic (P), economic (A), and technological $(\mathrm{T})$ factors on the environment is mainly postulated in the IPAT model ( $\mathrm{I}=\mathrm{PAT})$, which was first proposed by Ehrlichand et al. [36]. The IPAT model is limited because it analyzes a problem by changing a factor while keeping others constant, resulting in proportionate impacts on the dependent variable [37-38]. To overcome these weaknesses, Dietz et al. [37] reformulated the IPAT model into a stochastic model (STIRPAT), which can statistically assess non-monotonic or non-proportional impacts of driving forces on the environment. York et al. [39] refined the STIRPAT model and expanded it by incorporating additional factors, such as quadratic terms or different components of P, A, or T. Presently, the STIRPAT model has been successfully used to analyze the effects of driving forces on a variety of environmental impacts [40-41]. The STIRPAT model allows factors to be added to assess their impact on environmental pressure. In the STIRPAT model, factors P, A, and T are decomposable. To further examine the impact of GSHPs, we extended the STIRPAT model by incorporating the U, E, IS, HA, and PI factors into the model. The improved STIRPAT model was changed as follows:

$$
\begin{gathered}
\ln (G S H P)=a_{0}+a_{1} \ln (P)+a_{2} \ln (U)+a_{3} \ln (A)+a_{4} \ln (E) \\
+a_{5} \ln (I S)+a_{6} \ln (T)+a_{7} \ln (H A)+a_{8} \ln (P I)+e
\end{gathered}
$$

... where GSHP represents floor area of GSHP projects, P refers to urban population, $U$ refers to urbanization level (expressed as population urbanization rate), A represents affluence (expressed as GDP per capita), E is per capita energy consumption, IS refers to industrial structure (expressed as the ratio of secondary industry to GDP), T is technology level (expressed as R\&D investment), HA is the central heating area, and PI is policy investment. The use of GSHPs can promote the role of emissions reduction. In the government's policy incentives, policies can promote the development of GSHPs. In 2005, policy recommendations were encouraging and in 2006, the policy was obvious and some achievements were achieved. PI is a dummy variable [43] and we set this variable as the value of 0 and 1 . Therefore, the policy investment before 2005 was set to be 0 and the policy investment after 2005 was set to be 1 . This paper selects policy investment as a variable to balance the use of ground source heat pump needs.

\section{PLS Method}

Partial least squares (PLS) is particularly useful when independent variables have a strong collinearity $[42,44]$. The method will extract the latent variables (integrated variables) $t_{i}\left(u_{i}\right)$ from $X(Y)$ variables and make the $t_{i}\left(u_{i}\right)$ represent original information in $\mathrm{X}(\mathrm{Y})$ as much as possible. In this paper, the dependent variable (Y) has the only one (GSHP); thus, the analytical process has been greatly simplified. Firstly, the PLS calculation process requires the standardization of the raw data $\mathrm{X}(\mathrm{Y})$; then the first component, $\mathrm{t}_{1}$, is extracted from standardized data (X). Secondly, the regression of $\mathrm{X}$ to $\mathrm{t}_{1}$ and the regression of $\mathrm{Y}$ to $\mathrm{t}_{1}$ are implemented in PLS. If the accuracy of the result of regression is satisfactory, the computation terminates; if unsatisfactory, the second component $\left(\mathrm{t}_{2}\right)$ needs to be extracted from the residual information of $\mathrm{X}$ and the second regression analysis is implemented. The regression is implemented repeatedly until satisfactory accuracy is achieved and the latent variables $t_{1}, t_{2} \ldots t_{m}$ are obtained [42, 44-45]. In this study, we directly adopted the software Simca 13, developed by the Umetrics Company, to perform PLS calculations. The input data were the same as those in the STIRPAT model.

There are two important tables or plots used to explain the applicability of the PLS method: the $t_{1} / t_{2}$ scatter plot (also called to be $\mathrm{T}^{2}$ oval plot) and $\mathrm{t}_{1} / \mathrm{u}_{1}$ scatter plot. In the $\mathrm{T}^{2}$ oval plot, $\mathrm{t}_{1}$ and $\mathrm{t}_{2}$ are the integrated or latent variables extracted from the $\mathrm{X}$ variables. They can represent the key information of $\mathrm{X}$ variables as much as possible and have a strong capacity to explain the $\mathrm{Y}$ variables as much as possible. If the $t_{1} / t_{2}$ relationship of the sample data is included in the oval, these sample data are homogeneous and good and can be accepted perfectly [42-44]. In the $t_{1} / u_{1}$ scatter plot, $u_{1}$ is the integrated or latent variable extracted from the $\mathrm{Y}$ variables. If the $\mathrm{t}_{1} / \mathrm{u}_{1}$ relationship of the sample data is nearly linear, the PLS linear regression model built is appropriate for studying the problem [42, 44-45].

In the PLS regression approach, VIP (variable importance in projection) better reflects the explanatory potential of each independent variable for each dependent variable. VIP shows the importance of every independent variable when explaining the dependent variable. If a predictor has a relatively small VIP value [46] (considering less than 0.8 to be "small"), then it is a prime candidate for deletion. The equation is:

$$
V I P_{j}=\sqrt{\frac{p}{R d\left(Y ; t_{1}, \ldots, t_{m}\right)} \sum_{h=1}^{m} R d\left(Y ; t_{h}\right) w^{2}{ }_{h j}}
$$

...where $\mathrm{VIP}_{\mathrm{j}}$ is the VIP of $\mathrm{x}_{\mathrm{j}}$; $\mathrm{p}$ is the number of independent variables; $\operatorname{Rd}\left(\mathrm{Y}_{\mathrm{t}}, \ldots, \mathrm{t}_{\mathrm{m}}\right)=\sum_{h=1}^{m} \operatorname{Rd}\left(Y ; t_{h}\right)$ is the accumulative explanatory capability; $\mathrm{t}_{1}, \ldots, \mathrm{t}_{\mathrm{m}}$ are components extracted in the variable $\mathrm{X} ; \mathrm{w}_{\mathrm{hj}}$ is the $\mathrm{j}$ of $\mathrm{w}_{\mathrm{h}}$, which was measured by the marginal contributions of $\mathrm{xj}_{\mathrm{j}}$ for constitution $\mathrm{t}_{\mathrm{h}}$, and for any $\mathrm{h}=1,2, \ldots, \mathrm{m}$,

$$
\sum_{j}^{p} w_{h j}^{2}=w_{h}^{\prime} w_{h}=1
$$




\section{Results and Discussion}

\section{Analysis of Floor Area of GSHPs}

Figure 1 shows the area of GSHPs and the area of central heating from 1998 to 2011. It can be found that both the GSHP and central heating area present upward trends despite some dips. The area of the GSHP application increased from $2 \times 10^{6} \mathrm{~m}^{2}$ to $2.4 \times 10^{8} \mathrm{~m}^{2}$. The growth is very slow from $2 \times 10^{6} \mathrm{~m}^{2}$ in 1998 to $2.6 \times 10^{7} \mathrm{~m}^{2}$ in 2006, while the area of GSHP application increases aggregately from $2.6 \times 10^{7} \mathrm{~m}^{2}$ in 2006 to $2.4 \times 10^{8} \mathrm{~m}^{2}$ in 2011. The central heating area showed a linear upward trend from $8.65 \times 10^{8} \mathrm{~m}^{2}$ in 1998 to $4.74 \times 10^{9} \mathrm{~m}^{2}$ in 2011 . However, the proportion of GSHP application accounted for was very small and increased from $0.23 \%$ in 1998 to $5.07 \%$ in 2011. In 2007 the proportion accounted for more than $1 \%$ of the central heating area. From 2006 to 2011 the use of GSHPs grew rapidly, mainly due to national policy incentives. In 2005 the National Development and Reform Commission listed geothermal generation and the use of geothermal heat pumps as key projects and geothermal drilling equipment as the recommended device for implementing the "Guidelines of Renewable Energy Industry Development." In the same year, the Ministry of Construction officially listed the technology of GSHPs as one of 10 new technologies in the construction industry. Although government and industry have made significant efforts, GSHP technology really started to develop after 2006.

In 2006 the Chinese government promulgated the "Technical Code for Ground-Source Heat Pump System," which provides specifications for the design, construction, and acceptance of GSHP system projects and ensures safe and reliable system operation. Implementing the "Renewable Energy Law" in 2006, the government explicitly stated the importance of geothermal heat pumps and encouraged enterprises to develop GSHP technology. In August, the "Interim Measures for the management of special funds for renewable energy development" clearly put forward an objective "to strengthen the management of special funds for renewable energy development, focusing on supporting solar energy, wind energy, geothermal energy development and utilization" and encouraged the enterprises to utilize the heating and cooling system of GSHPs in new building construction. In the "Eleventh Five-Year Plan of Land Resources," the government promoted the development of GHPs and the potential evaluation of prospects for development zones. After 2006 China attached great importance to the development of GHPs. "Notice of the Ministry of Construction and the Ministry of Finance on the implementation comments for application of renewable energy in buildings" listed GHP application among the key technological fields. China's National Climate Change Program, "National Renewable Energy Long-Term Planning," the Ordinance on Civilbuilding Energy Conservation, and a series of other regulations promulgated that GSHPs are the main direction of the future development of geothermal resources.

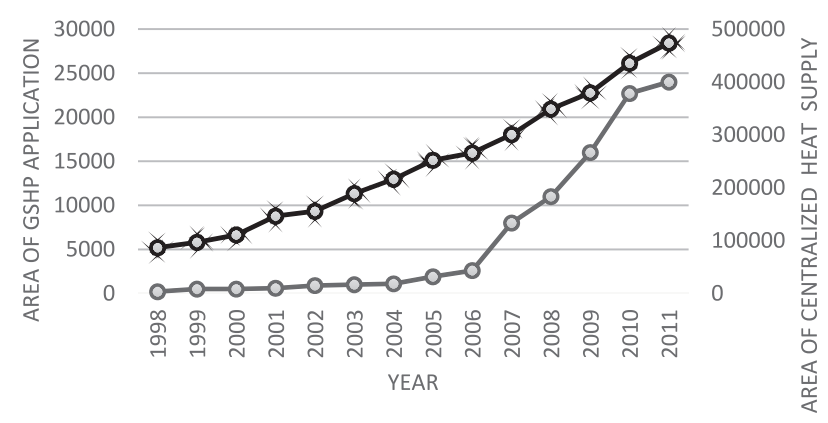

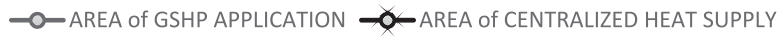

Fig. 1. Area of GSHP application and central heat supply.

\section{Influencing Factor of GSHP Application}

The influencing factors of GSHP applications are shown in Table 2, which shows a strong collinearity among these independent variables.

The PLS method was used in this paper to reduce the collinearity impact of these variables. First, the applicability of the PLS method should be tested by checking the $\mathrm{T}^{2}$ oval plot and the $\mathrm{t}_{1} / \mathrm{u}_{1}$ scatter plot. The sample data in this paper are acceptable because there is no inhomogeneous point in the $\mathrm{T}^{2}$ oval plot of the sample data (Fig. 3). It is obvious that the $t_{1} / u_{1}$ relationship of the sample data is nearly linear (Fig. 2); thus, the PLS linear regression model built is reasonable to the study problem of this paper. The observed versus the predicted plots showed a perfect linear relationship between the predictive value $\left(\mathrm{Y}_{\text {Pred }}\right)$ and the actual value $\left(\mathrm{Y}_{\text {Var }}\right)$ (Fig. 4). This means that the explanation effect of the results made by the PLS method is acceptable. The R2VY (cum) denotes the cumulative fraction of the variation of the $Y$ variables explained after the selected component. $\mathrm{R}^{2} \mathrm{VY}$ (cum) reached 0.948 after the $\mathrm{t}_{1}$ component was extracted, which means that the extracted components $\mathrm{t}_{1}$ from the $\mathrm{X}$ variables can explain $94.8 \%$ of the information of the $Y$ variables. When $t_{1}$ and $t_{2}$ were extracted, they can explain $97.5 \%$ of the information of the $\mathrm{Y}$ variables. When the three components $t_{1}, t_{2}$ and $t_{3}$ were extracted from the $X$ variables, they can explain $98.0 \%$ of the information of the Y variables. These R2VYs (cum) also showed a good explanation effect of the PLS method.

Moreover, Table 3 shows the regression coefficients of the PLS method. It can be seen that the coefficient of P was 0.1358 after the $t_{1}$ component was extracted. When $t_{1}$ and $t_{2}$ were extracted, the coefficient had changed to 0.1503 , and when $t_{1}, t_{2}$, and $t_{3}$ were extracted, the coefficient again changed to 0.1105 . These showed that a $1 \%$ change in population (P) may induce about 0.1045 0.1503 percentage change in GSHP or P had an elasticity of about 0.1105-0.1503. Similarly, U, A, E, T, HA, and PI had an elasticity of $0.1178-0.1539,0.1384-0.2300$, $0.1130-0.1350, \quad 0.1376-0.1685, \quad 0.0879-0.1419$, and $0.1253-0.2873$, respectively. This suggests that $\mathrm{P}, \mathrm{U}, \mathrm{A}$, $\mathrm{E}, \mathrm{T}, \mathrm{HA}$, and PI may be the major influencing factors of GSHP application. P, U, A, E, T, HA, and PI have positive 
Table 2. OLS regression of influencing factors of GSHP application.

\begin{tabular}{|c|c|c|c|c|c|c|c|}
\hline \multirow{2}{*}{$($ Constant $)$} & $\mathrm{B}$ & $\mathrm{SE}(\mathrm{B})$ & $\mathrm{Beta}$ & $\mathrm{t}$ & Sig. & Tolerance & VIF \\
\cline { 2 - 8 } & $-3,103.042$ & $3,136.275$ & - & -0.989 & 0.368 & - & - \\
\hline $\mathrm{P}$ & 276.559 & 278.673 & 4.227 & 0.992 & 0.367 & 0.000 & $7,359.497$ \\
\hline $\mathrm{U}$ & -21.182 & 38.304 & -1.813 & -0.553 & 0.604 & 0.000 & $4,360.059$ \\
\hline $\mathrm{A}$ & 5.805 & 4.063 & 2.044 & 1.429 & 0.212 & 0.001 & 830.119 \\
\hline E & 1.013 & 4.219 & 0.209 & 0.24 & 0.82 & 0.003 & 306.332 \\
\hline IS & -13.734 & 13.207 & -0.164 & -1.04 & 0.346 & 0.099 & 10.073 \\
\hline T & -4.173 & 4.709 & -2.317 & -0.886 & 0.416 & 0.000 & $2,773.019$ \\
\hline HA & -3.688 & 3.243 & -1.288 & -1.137 & 0.307 & 0.002 & 520.326 \\
\hline PI & 0.121 & 0.519 & 0.039 & 0.233 & 0.825 & 0.088 & 11.313 \\
\hline
\end{tabular}

effects on GSHP demand; this indicates that the index of urban population growth, economic development, increasing energy consumption, the development of GSHP technology, and policy input have increased the demand of GSHP application.

However, the coefficients of IS had changed from positive to negative, which means that its impact on GSHP application is not important or it is not the major factor of GSHP application; this indicates that the change in the number of residents has no effect on the demand for GSHP. Regarding this point, the same results could be

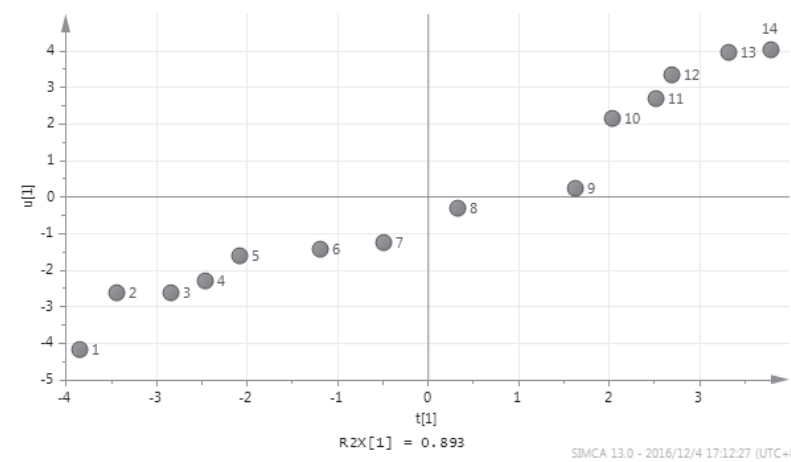

Fig. 2. $\mathrm{t}_{1} / \mathrm{u}_{1}$ scatter plot.

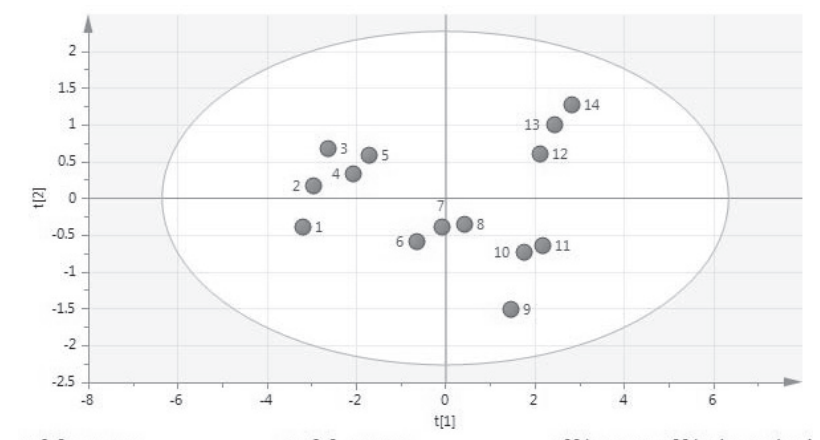

Fig. 3. $\mathrm{T}^{2}$ oval plot. easily concluded from the VIP plot, in which the statistical importance of these independent variables $(\mathrm{X})$ relative to the dependent variables $\mathrm{Y}$ is revealed in a graphic representation according to their VIP values (Fig. 5). Because the VIP's values of P, U, A, E, T, and HA are greater than 1, they may be the major influencing factors of GSHP application (Y). Among them, the per capita GDP (A) on the growth of demand for GSHPs has the

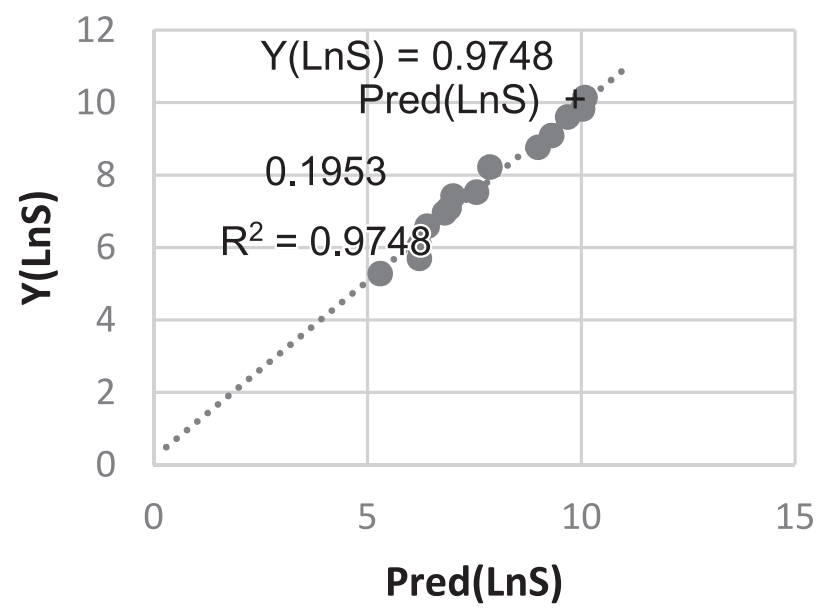

Fig. 4. Observed vs. predicted plots.

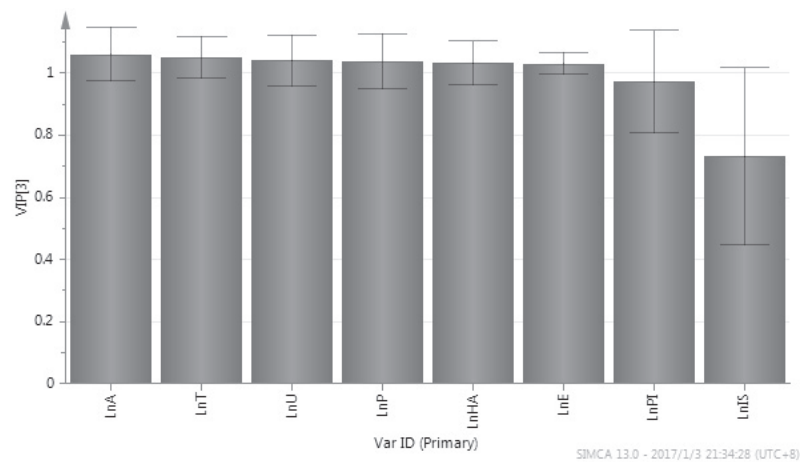

Fig. 5. The VIP plot. 
Table 3. Coefficients of the PLS method.

\begin{tabular}{|c|c|c|c|}
\hline Components extracted & $\mathrm{t}_{1}$ & $\mathrm{t}_{1}$ and $\mathrm{t}_{2}$ & $\mathrm{t}_{1}, \mathrm{t}_{2}$ and $\mathrm{t}_{3}$ \\
\hline Constant & 4.8494 & 4.8494 & 4.8493 \\
\hline P & 0.1358 & 0.1503 & 0.1105 \\
\hline U & 0.1361 & 0.1539 & 0.1178 \\
\hline A & 0.1384 & 0.1845 & 0.2300 \\
\hline E & 0.1350 & 0.1254 & 0.1130 \\
\hline IS & 0.0757 & -0.1336 & -0.1500 \\
\hline T & 0.1375 & 0.1685 & 0.1651 \\
\hline HA & 0.1349 & 0.1419 & 0.0879 \\
\hline PI & 0.1253 & 0.1648 & 0.2873 \\
\hline
\end{tabular}

largest value; this indicates the need for people's living standards to increase the demand for GSHPs, and A is the most important factor of GSHP application.

PI is close to 1 , which indicates that policy input is one of the important factors of GSHP, but the effect is not obvious. Furthermore, because the VIP values of IS stayed in the interval of $0.5-1$, its impact on GSHP application (Y) cannot be determined or was not important [42-44].

There are two factors related to population, namely urban population and population structure. The population structure factor has a similar effect on the use of GSHPs as the urban population. $\mathrm{P}$ and $\mathrm{U}$ had an elasticity of $0.1105-0.1503$ and $0.1178-0.1539$. The influence degree of the two factors is $0.26 \%$ and $0.07 \%$, respectively, with the former being much higher than the latter. The effect of urbanization on the use of GSHPs has multiple effects. In this model, the impact of the residents' consumption behavior, which was caused by the changes in population structure, affects GSHP application. Compared with the growth of other factors, the urban population growth in China is relatively small, and the urban population has a limited explanatory effect on the growth of the demand of GSHPs. The increase in per capita energy consumption has contributed to the use of GSHPs. A 1\% change in energy consumption per capita may induce about a $0.1130-0.1350$ percentage change in GSHP application. R\&D technology improves the use of the GSHP system. Development of technical equipment promotes the development of new energy, thus promoting the development of a GSHP system. Technological innovation is the key to energy-saving emission reduction. From energy-saving technologies to the development and use of new energy, energy-saving products and services have become the focus of the low-carbon energy strategy. We should integrate technology resources, strengthen and coordinate regional GSHP technology innovation, promote production-study-research cooperation and technology transfer, and strengthen the GSHP industry layout and system innovation to improve the competitive ability of carbon emissions. The increase in central heating promotes the use of GSHPs. The central heating area had a linear upward trend, and the growth of the central heating area promotes the demand for GSHPs. The increase in the central heating area is the direct cause of the increase in demand for building GSHPs. The increase in the central heating area will inevitably bring increase energy consumption for GSHP systems.

\section{Conclusions}

Implementing GSHP systems is one of the most promising efforts to reduce fossil fuel consumption and $\mathrm{CO}_{2}$ emissions. In China, GSHP systems have been receiving an increasing amount of attention and the number of applications has grown rapidly in recent years [1]. The area of GSHP application has increased 12 times between 1998 and 2011, while the central heating area has increased five times. The proportion of the central heating area in GSHP application had increased to $5 \%$ in 2011, but it is still very low. In particular, GSHP application has had the greatest increase since 2005, which means that GSHP application has become a remarkable development because the Chinese government has been paying much more attention to GSHPs.

On the basis of the STIRPAT model, this paper selected the following influencing factors: population, urbanization, GDP per capita, energy consumption per capita, industrial structure, $\mathrm{R} \& \mathrm{D}$, central heating area, and policy input from the government. Compared with the STIRPAT model, the analysis results of the PLS method are more reasonable and acceptable because the collinearity among these factors themselves cannot be avoided in the STIRPAT model, which can bring some negative impacts to the ultimate results; but the collinearity can hardly impact the PLS method. The analysis results of GSHP's influencing factors by the PLS method showed that the major factors of GSHP application were P, U, A, E, T, HA, and PI. The most important influencing factor was A (its elasticity was the highest), and the effect of other factors (the elasticity of IS was low) almost can be ignored. Thus, the results using the PLS method are more reasonable and acceptable.

The use of GSHPs has been growing rapidly. GSHP has the potential for significant unit energy savings (per-installation savings), and generally has efficiency advantages; however, there are some challenges. The following suggestions are provided to overcome these encumbrances and promote the market growth of GSHPs in China:

Increased support for R\&D on GSHPs, including domestic and international partnerships. A fully developed financial incentive system should be established as soon as possible to promote the R\&D and application of GSHP systems.

Large GSHP installations providing a district heating and cooling system to the community and promoting the proportion of building areas with GSHPs.

Maximize the use of GSHPs required for new construction. Plan installation-specific design and engineering of the 
ground loop.

Increase the awareness of creating zero-energy buildings with GSHPs.

\section{Acknowledgements}

The authors gratefully acknowledge the support provided by the National Natural Science Foundation of China under grant No. 71173200, National Science and Technology Major Project under grant No. 2016ZX05016005-003, and the Development and Research Center of China Geological Survey under grant No. 12120114056601

\section{References}

1. YANG W., ZHOU .J, XU W., ZHANG G.Q. Current status of ground-source heat pumps in China. Energy Policy, 38, 323, 2010.

2. YANG X., SONG Y., WANG G., WANG W. A comprehensive review on the development of sustainable energy strategy and implementation in China. IEEE Trans Sustain Energy, 1 (2), 57, 2010.

3. CROMPTON P., WU Y. Energy consumption in China: past trends and future directions. Energy Economics, 27, 195, 2005.

4. LI Z.S., ZHANG G.Q., LI D.M., ZHOU J., LI L.J., LI L.X. Application and development of solar energy in building industry and its prospects in China. Energy Policy, 35, 4121, 2007.

5. LIAO P.C., ZHANG K.N., WANG T., WANG Y.Q. Intergrating bibliometrics and roadmapping: a case of strategic promotion for the ground source heap pump in China. Renewable and sustainable energy reviews, 57, 292, 2016.

6. HEPBASLI A., AKDEMIR O. Energy and exergy analysis of a ground source heat pump system. Energy Convers. Manag., 45 (5), 737, 2004.

7. SARBU I, SEBARCHIEVICI C. General review of groundsource heat pump systems for heating and cooling of buildings. Energy and buildings, 70, 441, 2014.

8. EPA. A short primer and environmental guidance for geothermal heat pumps. In: Environmental Protection Agency, 430-K-97-007, 1997.

9. HUANG Y.X., LIAO P.C., TSAI S.H. Modeling the relationships of factors affecting dissemination of ground source heat pump (GSHP) in China. Adv Mater Res, 723, 976, 2013.

10. LUO J., ROHNA J., BAYER M., PRIESS A., WILKMANN L., XIANG W. Heating and cooling performance analysis of a ground source heat pump system in Southern Germany. Geothermics, 53, 57, 2015.

11. ZHANG Y., CHOUDHARY R., SOGA K. Influence of GSHP system design parameters on the geothermal application capacity and electricity consumption at cityscale forWestminster, London. Energy and Buildings, 106, $3,2015$.

12. KECEBAS A. Energetic, exergetic, economic and environmental evaluations of geothermal district heating systems: An application. Energy Conversion and Management, 65, 546, 2013.

13. BLUM P., CAMPILLO G., KOLBEL T. Techno-economic and spatial analysis of vertical ground source heat pump systems in Germany. Energy, 36, 3002, 2011.

14. COL D.D., AZZOLIN M., BENASSI G., MANTOCAN M. Energy efficiency in a ground source heat pump with variable speed drives. Energy and Buildings, 91, 105, 2015.

15. WANG Z.H., WANG F.H., MA Z.J., WANG X.K., WU X.Z. Research of heat and moisture transfer influence on the characteristics of the ground heat pump exchangers in unsaturated soil. Energy and Buildings, 130, 140, 2016.

16. MEHRIZI A.A., PORKHIAL S., BEZYAN B., LOTFIZADEH H. Energy pile foundation simulation for different configurations of ground source heat exchanger. International Communications in Heat and Mass Transfer, 70, 105, 2016.

17. SONI S.K., PANDEY M., BARTARIA V.N. Hybrid ground coupled heat exchanger systems for space heating/cooling applications:A review. Renewable and Sustainable Energy Reviews, 60, 724, 2016.

18. NOOROLLAHI Y., BIGDELOU P., POURFAYAZ F., YOUSEFI H. Numerical modeling and economic analysis of a ground source heat pump for supplying energy for a greenhouse in Alborz province, Iran. Journal of Cleaner Production, 131, 145, 2016.

19. QIAN H., WANG Y.G. Modeling the interactions between the performance of ground source heat pumps and soil temperature variations. Energy for Sustainable Development, 23, 115, 2014

20. OZGENER O., HEPBSLI A. A parametrical study on the energetic and exergetic assessment of a solar-assisted vertical ground-source heat pump system used for heating a greenhouse. Build Environ, 42, 11, 2007.

21. NAGANO K., KATSURA T., TAKEDA S. Development of a design and performance prediction tool for the ground source heat pump system. Appl. Therm. Eng., 26, 1578, 2006.

22. ESEN H., INALLI M., ESEN M. Technoeconomic appraisal of a ground source heat pump system for a heating season in eastern Turkey. Energy Convers. Manag., 47, 1281, 2006.

23. MORRONE B., COPPOLA G., RAUCCI V. Energy and economic savings using geothermal heat pumps in different climates. Energy Conversion and Management, 88, 189, 2014.

24. KECEBAS A., ALKAN M.A., ABANOVA I., YUMURTAC $M$. Energetic and economic evaluations of geothermal district heatin gsystems by using ANN. Energy Policy, 56, 558, 2013.

25. BADESCU V. Economic aspects of using ground thermal energy for passive house heating. Renew Energy, 32, 895, 2007.

26. SHEN P.Y., LUKES J.R. Impact of global warming on performance of ground source heat pumps in US climate zones. Energy Conversion and Management, 101, 632, 2015.

27. GREENING B., AZAPAGIC A. Domestic heat pumps: Life cycle environmental impacts and potential implications for the UK. Energy, 39, 205, 2012.

28. KORONEOS C.J., NANAKI E.A. Environmental impact assessment of a ground source heat pump system in Greece. Geothermic,s 65, 1, 2017.

29. RUSSO S.L., BOFFA C., CIVITA M.V. Low-enthalpy geothermal energy: anopportunity to meet increasing energy needs and reduce $\mathrm{CO} 2$ and atmospheric pollutant emissions in Piemonte, Italy. Geothermics, 38, 254, 2009.

30. BLUM P., CAMPILLO G., MONCH W., KLBEL T. CO, savings of ground sourceheat pump systems - a regional analysis. Renew. Energy, 35, 122, 2010.

31. AKELLA A.K., SAINI R.P., SHARMA M.P. Social, 
economical and environmentalimpacts of renewable energy systems. Renew. Energy, 34, 390, 2009.

32. BAYER P., SANER D., BOLAY S., RYBACH L., BILUM

P. Greenhouse gas emission savings of ground source heat pump systems in Europe: A review. Renewable and Sustainable Energy Reviews, 16, 1256, 2012.

33. CARVALHO A.D., MENDRINOS D., ALMEIDA A.T.D. Ground source heat pump carbon emissions and primary energy reduction potential for heating in buildings in Europe-results of a case study in Portugal. Renewable and Sustainable Energy Reviews, 45, 755, 2015.

34. SIVASAKTHIVEL T., MURUGESAN K., SAHOO P.K. Study of technical, economical and environmental viability of ground source heat pump system for Himalayan cities of India. Renewable and Sustainable Energy Reviews, 48, 452, 2015.

35. KHARSEH M., ALTORKMANY L., ALKHAWAJA M., HASSANI F. Analysis of the effect of global climate change on ground source heat pump systems in different climate categories. Renewable Energy, 78, 219, 2015.

36. EHRLICH P.R., HOLDREN J.P. Impact of population growth. Science, 191 (3977), 1212, 1971.

37. DIETZ T., ROSA E.A. Rethinking the environmental impacts of population, affluence and technology. Hum Ecol Rev, 1, 277, 1994.

38. SHI A. The impact of population pressure on global carbon dioxide emissions, 1975-1996:evidence from pooled crosscountry data. Ecol Econ, 44 (1), 29, 2003.

39. YORK R., ROSA E.A., DIETZ T. STIRPAT, IPAT and
ImPACT: analytic tools for unpacking the driving forces of environmental impacts. Ecol Econ, 46 (3), 351, 2003.

40. FAN Y., LIU L., WU G., WEI Y. Analyzing impact factors of $\mathrm{CO} 2$ emissions using the STIRPAT model. Environ Impact Assess, 26 (4), 377, 2006.

41. LIU Y., ZHOU Y., WU W. Assessing the impact of population, income and technology on energy consumption and industrial pollutant emissions in China. Appl Energy, 155, 904, 2015.

42. WANG H. Partial Least Squares Regression: Method and Applications. National Defence Industry Press, Beijing, China. 200, 1999 [In Chinese].

43. KEMP F. Applied multiple regression/correlation analysis for the behavioral sciences. Journal of the Royal Statistical Society, 52 (4), 691-691, 2003.

44. WANG H. Linear and Nonlinear Methods of Partial Least Squares Regression. National Defence Industry Press, Beijing, China. 279, 2006 [In Chinese].

45. JIA J.S., DENG H.B., DUAN J., ZHAO J.Z. Analysis of the major drivers of the ecological footprint using the STIRPAT model and the PLS method. Ecological Economics, 68, 2818, 2009

46. WOLD S. PLS for multivariate linear modeling. QSAR: chemometric methods in molecular design Methods and principles in medicinal chemistry. Weinheim, Germany 7 Verlag-Chemie; 1994. 